\begin{tabular}{|c|c|c|}
\hline $\begin{array}{l}\text { PKS } \\
\text { PUBLIC } \\
\text { KNOWLEDGE } \\
\text { PROSECT }\end{array}$ & $\begin{array}{c}\text { REVISTA DE GEOGRAFIA } \\
\text { (RECIFE) } \\
\text { http://www.revista.ufpe.br/revistageografia }\end{array}$ & 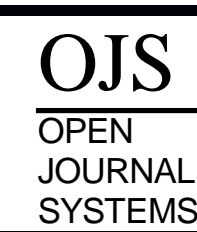 \\
\hline
\end{tabular}

\title{
CINEMA E GEOGRAFIA: O FILME COMO INSTRUMENTO DIDÁTICO NO ENSINO DE GEOGRAFIA
}

\author{
Renata Michele Messias ${ }^{1}$, Josué Alencar Bezerra ${ }^{2}$ \\ ${ }^{1}$. Discente do Programa de Pós-Graduação em ensino da Universidade do Estado do Rio Grande do Norte \\ (UERN), Campus CAMEAM, Pau dos Ferros.E-mail: renata.michelly@hotmail.com \\ ${ }^{2}$.Prof. Dr. do Curso de Geografia da Universidade do Estado do Rio Grande do Norte (UERN), \\ Campus de Pau dos Ferros-RN. E-mail:josueabezerra@gmail.com
}

Artigo recebido em 17/02/2017e aceito em 18/03/2018

\begin{abstract}
RESUMO
Neste trabalho discutimos a relação entre cinema e Geografia e suas colaborações como instrumento didáticopedagógico no ensino da disciplina. Destacamos as principais contribuições e eventuais problemas a serem resolvidos na utilização de filmes em sala de aula. Cogitamos ser este um recurso didático-pedagógico com grandes potencialidades e contribuições para o processo de ensino-aprendizagem e de formação crítica dos sujeitos, mas que ainda encontra resistência para adentrar no ambiente escolar ocasionadas pelo seu mau uso. Autores como Duarte (2009), Holleben (2007), Napolitano (2015) e Barbosa (2004) foram fundamentais como aporte teórico para compreendermos a importância da relação entre o filme e o ensino de Geografia. Esta pesquisa seguiu os procedimentos com um estudo de caso nas turmas do $6^{\circ}$ A e $9^{\circ}$ ano da Escola Municipal Abraão Cavalcante Bessa, localizada no município de Taboleiro Grande $(\mathrm{RN})$, para investigar se o filme é um instrumento usado na escola, na disciplina de Geografia, e quais os resultados alcançados com a sua utilização. $\mathrm{O}$ trabalho propõe a indicação de alguns filmes que possam ser trabalhados nas séries investigadas, utilizando os Parâmetros Curriculares Nacionais (PCN's) de Geografia como referência para identificar os temas para o ensino desta disciplina no terceiro e quarto ciclos do Ensino Fundamental.
\end{abstract}

Palavras-chave: Cinema; Ensino; Instrumento Didático; Geografia.

\section{CINEMA AND GEOGRAPHY: THE FILM AS A DIDACTIC INSTRUMENT IN GEOGRAPHY EDUCATION}

\begin{abstract}
In this work we discuss the relationship between cinema and geography and their collaborations as a didacticpedagogical instrument in the teaching of the discipline. We highlight the main contributions and eventual problems to be solved in the use of films in the classroom. We assume this to be a didactic-pedagogical resource with great potentialities and contributions to the teaching-learning process and the critical formation of the subjects, but still finds resistance to enter the school environment caused by its misuse. Authors such as Duarte (2009), Holleben (2007), Napolitano (2015) and Barbosa (2004) were fundamental as a theoretical contribution to understand the importance of the relationship between cinema and geography teaching. This research followed the qualitative and quantitative procedures, with a case study in the 6th and 9th grade classes of Abraão Cavalcante Bessa Municipal School, located in the municipality of Taboleiro Grande (RN), to investigate whether the film is an instrument used in school, In the discipline of Geography, and what the results achieved with its use. The work proposes the indication of some films that can be worked in the series investigated, using the National Curricular Parameters (PCN's) of Geography as reference to identify the subjects for the teaching of this discipline in the third and fourth cycles of Elementary School.
\end{abstract}

Keywords: Cinema; Teaching; Didactic Instrument; Geography 


\section{INTRODUÇÃO}

O cinema tem desempenhado papel de destaque na sociedade atual. Atendendo a um público variado de crianças, jovens e adultos, o hábito de assistir filmes faz parte do cotidiano de muitas pessoas, influenciando direta ou indiretamente formas de pensar, modos de agir, o comportamento e vestimentas da sociedade.

Sobre a importância desse recurso, Duarte (2009, p.16) afirma que "Ver filmes, é uma prática social tão importante, do ponto de vista da formação cultural e educacional das pessoas, quanto a leitura de obras literárias, filosóficas, sociológicas e tantas mais”. Neste sentido, o filme como uma mídia presente no cotidiano da sociedade moderna não pode ser ignorado pela escola.

Salvo a sua importância, o filme ainda encontra resistência e obstáculos para adentrar no ambiente escolar por seu uso ser considerado como sinônimo de "enrolação" ou como mero instrumento para ilustração de conteúdos. Neste trabalho, fazemos uma discussão sobre a inserção de filmes no ensino em geral e, especificadamente, no ensino de Geografia.

Partindo desse pressuposto, este trabalho buscou discutir a relação entre cinema e ensino de Geografia e suas contribuições como instrumento didático-pedagógico no ensino fundamental. Para tanto, selecionamos a Escola Municipal Abraão Cavalcante Bessa, localizada em Taboleiro Grande (RN), única que oferta este nível de ensino no município, com o objetivo de analisar a importância da inserção do cinema no ensino de Geografia como recurso metodológico em sala de aula. Também buscamos identificar as principais contribuições e eventuais problemas na utilização de filmes como recurso didático nas aulas de geografia, bem como investigar como/se são trabalhados filmes na disciplina de Geografia no Ensino Fundamental II da Escola Municipal Abraão Cavalcante Bessa para, em seguida, reunir propostas de filmes como sugestão para discussão de temas da Geografia que compõe o currículo escolar do Ensino Fundamental II.

O interesse por esta temática se deu pela experiência que passamos durante nossa vida estudantil e acadêmica em que, muitas vezes, ainda no ensino básico, presenciamos o uso do filme na sala de aula apenas como "tapa buraco", para preencher a ausência de professores, ou quando os mesmos não haviam planejado nada para a realização das aulas.

Para a realização deste trabalho foi executada uma pesquisa bibliográfica, investigando o surgimento do cinema e seu desenvolvimento como a técnica, arte e meio de comunicação de massa tendo como aporte teórico autores, como Bernadet (2000), abordando 
as diversas configurações do cinema; e Mascarello (2006), trazendo a história do cinema mundial.

Já nas discussões entre cinema e ensino nos apoiamos principalmente em Napolitano (2015), que trata dos procedimentos e orientações para o uso do filme na sala de aula; em Duarte (2009), quando discute o filme como instrumento essencial para a inserção dos valores culturais e sociais; em Holleben (2007), quando argumenta ser possível e de grande necessidade o dialogo entre ambos; em Barbosa (2004) e Pontuschka, Paganelli, e Cacete (2009), que trazem essa discussão da utilização de filmes para o âmbito da Geografia. Dessa forma, subdividimos a pesquisa, observando o aporte teórico em categorias, em que retomamos a aspectos históricos como surgimento do cinema e processo de popularização dos filmes. No segundo momento, direcionamos a discussão sobre a relação do filme com a educação. E, por fim, enfocamos para as possibilidades de uso do filme na disciplina de geografia.

Após uma breve caracterização da escola campo de estudo localizada em Taboleiro Grande, ver (figura 01), apresentaremos os resultados de um estudo de caso, “[...] caracterizado pelo estudo profundo e exaustivo de um ou poucos objetos, de maneira que permita seu amplo e detalhado conhecimento" (GIL, 1988, p.58).

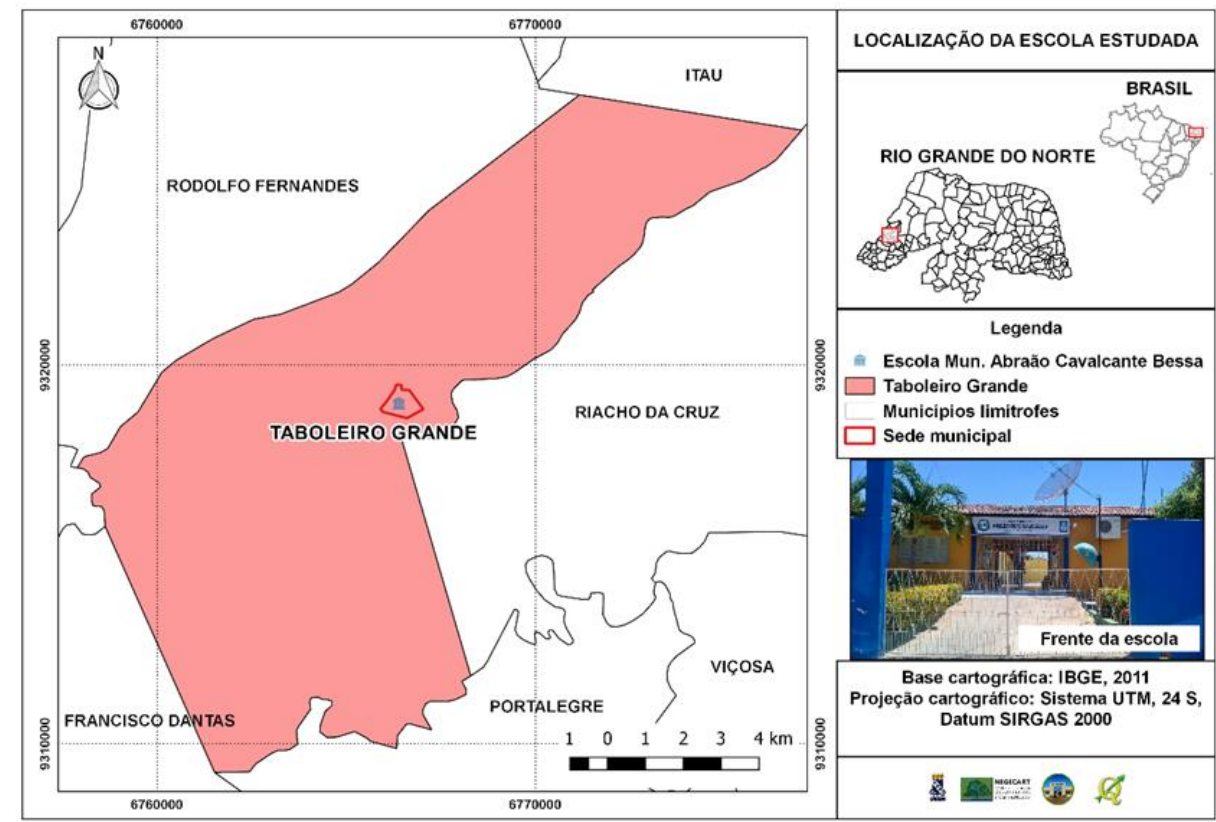

Figura 01: Taboleiro Grande (RN): localização da Escola Municipal Abraão Cavalcante Bessa. Fonte: Base Cartográfica, IBGE (2011). Cartografia de José Antônio Silva Filho, 2016. 
A partir da observação, entrevistas e questionários nas turmas do $6^{\circ}$ ano A e $9^{\circ}$ ano do Ensino Fundamental II na Escola Municipal Abraão Cavalcante Bessa, investigamos se o filme é utilizado na escola, no ensino de Geografia, e como se dá sua utilização e os resultados alcançados através do uso desse instrumento.

A pesquisa in loco se dividiu em dois momentos: o primeiro em forma de entrevista semi-estruturada com o professor de Geografia, a fim de investigar se o filme é utilizado na disciplina, os pontos positivos e negativos que ele observa na utilização desse instumento como recurso didático-pedagógico. No segundo momento, através de um questionário composto por (07) perguntas abertas e de múltiplas escolas, aplicado com os alunos do $6^{\circ}$ ano "A" e $9^{\circ}$ ano "turma única", perfazendo um total de 43 alunos.

Este recorte buscou identificar a relação dos alunos com os filmes no seu cotidiano, questionando quantos filmes eles assistem mensalmente, qual a modalidade que mais lhe interessam e o entendimento desse público acerca do uso desse intrumento no ensino de Geografia.

\section{O PAPEL DO CINEMA NA SOCIEDADE ATUAL: AS TEMPORALIDADES DA SÉTIMA ARTE}

O cinema tem desempenhado um papel de destaque na sociedade atual. Seja nas salas de projeções dos cinemas ou na comodidade de nossa casa, os filmes estão sempre ao nosso alcance na tevê aberta, na internet, em programas e serviços de assinatura. As formas como eles chegam até nós são diversas, atendendo a um público variado de crianças, jovens e adultos.

Mas, afinal o que é o cinema? Segundo Ladim (2008), não existe um conceito de cinema terminado, visto que este experimentou várias transformações ao longo dos anos, acompanhando as mutações históricas, tecnológicas e culturais a que ele esteve sujeito. Ainda respondendo essa questão, Bernadet (2000, p. 187), no livro O que é Cinema, diz: "No final do livro vocês não sabem. Eu também, não”, para tentar ilustrar o quão difícil ou até pretensioso seria atribuí-lo um conceito pronto e acabado, por ser um recurso caracterizado pela sua transitoriedade e constante mutação.

O cinema não é apenas uma máquina de contar e reproduzir histórias, criada apenas para entreter, emocionar e distrair. Desde o seu surgimento, o cinema vem influenciando gerações, apesar de todas as transformações e adaptações ocorridas desde o seu surgimento. 
Ao abordar o cinema na atualidade e as suas diversas facetas, Christofoletti (2009, p. 607) destaca que:

\begin{abstract}
Passado mais de um século de seu surgimento como arte-técnica-mídiaindústria o cinema se coloca na vida contemporânea não apenas como entretenimento ou negócio, mas também como linguagem formadora de opinião, propagadora de valores e aparato pedagógico. O desenvolvimento tecnológico fez da arte de iludir (afinal, é uma ilusão óptica: o estático que se torna movimento) uma importante ferramenta de disseminação ideológica [...] O cinema alcança dimensões que podem ser medidas pelas cifras bilionárias, pelas platéias na escala dos milhões e pela perenidade das imagens que lança no imaginário popular.
\end{abstract}

A indústria cinematográfica movimenta a economia de diversos países, gerando lucros grandiosos, ao passo que "[...] em 2015 a bilheteria do cinema mundial bateu um recorde de: US\$ 38 bilhões em arrecadação [...] Nos Estados Unidos foram arrecadados US\$ 11 bilhões, com um crescimento de 48,7\% se comparado a 2014" (ROMARIZ, 03/01/2016 UOL). Também é a grande responsável pela propagação de ideologias, já que os filmes são construções históricas, produções culturais que carregam traços da época da sua produção, que influenciam direta ou indiretamente formas de pensar, modos de agir, o comportamento e vestimentas da sociedade, principalmente, de jovens e crianças que sofrem maior influência dos meios de informação e comunicação.

Ao constatarmos que o cinema e suas obras fílmicas podem se constituirem em instrumentos de manipulação e disseminação, percebemos que, ao longo dos anos, ele vem ditando gostos e costumes, em âmbito global. "Filmes não são eventos culturais autônomos, é sempre a partir de mitos, crenças, valores, e práticas sociais das diferentes culturas que narrativas orais, escritas ou audiovisuais ganham sentido" (DUARTE, 2009, p. 44).

Quanto a importância do cinema, campo no qual a arte, a cultura, a política e tantas outras áreas pertinentes se apresentam de variadas formas a públicos heterogêneos: ficção científica, comédia, terror, ação/aventura, romances, documentários, dos comerciais aos específicos para fins didáticos. São muitos os gêneros disponíveis produzidos para atender de um público mais flexível ao mais exigente.

E como e quando surgiu essa arte e expressão cultural que é responsável por cativar e fascinar gerações e gerações? Como eram os primeiros filmes? O que eles abordavam? Como eram feitos? Onde eram exibidos? São questionamentos norteadores para entendermos o surgimento e a configuração atual do cinema moderno. São indagações que buscaremos responder a seguir ao tratar das diversas temporalidades do cinema.

\begin{tabular}{lll}
\hline Messias e Bezerra, 2018 & 328
\end{tabular}


O cinema como arte, entretenimento e veículo de informação e frutos da indústria cinematográfica, tem seus primeiros passos demarcados em 28 de dezembro de 1895, data essa em que aconteceu a primeira exibição pública de cinema, no Gran Café, em Paris. Na ocasião, os irmãos Lumière, Auguste e Louis, exibiram em uma tela branca, a um público composto por mais de cem pessoas, um filme curto, filmado com uma câmera parada em preto e branco e sem som (BERNADET, 2000). A produção era: "Chegada de um trem à estação de la Ciotat"- um espetáculo de luzes e movimentos (HOLLEBEN, 2007).

O evento supracitado marca o nascimento oficial do cinema, na ocasião o público viu, em imagens, breves testemunhos da vida cotidiana. Porém, antes disso, em 1889, nos Estados Unidos da América, Thomas Alva Edison criou o Kinetoscópio: uma caixa de madeira na qual uma película de 35 milímetros perfurada girava numa sucessão de fotos que davam a impressão de movimento contínuo (HOLLEBEN, 2007). A invenção de Edison prenunciava o cinema dos Lumiére, com a diferença que as imagens não eram projetadas (Ibid.).

Em janeiro de 1898, na cidade de São Paulo acontecia a primeira exibição do cinema no Brasil (BUZZO, 2004). Semelhantemente as primeiras seções de cinema em todo o mundo, eram exibidos filmes curtos de alguns minutos de duração que eram, em sua maioria, registros do cotidiano "[...] a saída de uma missa, a derrubada de um muro, um jardim italiano; enfim, o registro da realidade constituía um espetáculo" (BUZZO, 2004, p.160).

A Sétima Arte, termo que foi designado por Ricciotto Canuto, em 1912, ao perceber que o cinema traria uma revolução cultural, pois reunia as outras seis artes conhecidas: dança, teatro, música, literatura, pintura e escultura. Essa expressão se popularizou e até hoje é utilizada para caracterizá-lo (HOLLEBEN, 2007).

Posteriormente, com a evolução da sua linguagem, a técnica e seus efeitos se sofisticaram, até chegar na fase atual, caracterizada por uma evolução dos temas, do conceito de personagens e da estrutura narrativa (Ibid.). Desde então, o cinema passou por diversas adaptações, como: os movimentos de palco, o início do cinema falado, avanço do estilo tradicional de projeções em preto e branco a incorporação da cor, a linguagem, vestimentas e figurinos, entre outras que o configuram tal qual conhecemos hoje.

Com a invenção de novas tecnologias como o vídeo cassete e mais adiante do DVD Player e sua disseminação popular, os filmes passaram a ser consumidos em ambientes externos as salas de exibição. A tecnologia da gravação e reprodução de fitas criou o mercado de vídeo doméstico, tornando o cinema uma mídia praticamente onipresente na vida da sociedade moderna (CHRISTOFOLETTI, 2009). 
Parafraseando Mascarello (2006, p.14), na introdução do seu livro História do Cinema Mundial, “[...] seja visto na sala de cinema, tevê, internet ou celular. O cinema, por muito tempo, seguirá fazendo História", construindo novas pontes, adaptando-se a novos públicos, encantando e influenciando gerações.

Entre as diversas facetas apresentadas pelo cinema, destacaremos a seguir uma que, ao longo dos anos, vem adentrando o universo da escola como meio de ilustrar e abordar de forma lúdica diversos temas e conteúdos, em um ambiente totalmente diferenciado das salas de exibições, transformando-o de um instrumento de lazer a um recurso didático-pedagógico, em que o seu grande diferencial está em se fazer presente no cotidiano do aluno.

\section{CINEMA E EDUCAÇÃO: PERSPECTIVAS E CONTRIBUIÇÕES}

Ao enfatizarmos a importância e a necessidade de uma relação existente entre cinema e educação, grifamos que "No mundo atual, é possível identificar ampla diversidade de linguagens num contexto marcado por uma infinidade de informações. A sociedade é, cada vez mais, uma sociedade da informação [...]" (PONTUSCHKA et al. 2009, p. 261). A escola, enquanto agente de formação humana e intelectual dos sujeitos, deve encontrar meios de proporcionar aos alunos uma formação que possibilite filtrar e interpretar essa série de informações descontextualizadas e fragmentadas que nos são postas através dos meios de comunicação modernos.

Nesse contexto, o cinema, com o uso de filmes na sala de aula, tem sido uma dessas novas metodologias que vêm adentrando o ensino de diversas disciplinas, como: História, indicada como uma das disciplinas mais habituadas ao uso de filmes, Geografia, Língua Portuguesa, Ciências, entre outras (NAPOLITANO, 2015).

Muitos autores, como Napolitano (2015) e Duarte (2009), visualizam o filme como um instrumento pedagógico lúdico, atraente e repleto de potencialidades. E recentemente observamos o surgimento de propostas mais sistematizadas que orientem o professor para utilização correta desse recurso. E, aliado a isso, Napolitano (2015) reforça a importância de se trabalhar com o filme na sala de aula, a partir do planejamento, execução, análise e debates. Bem como suas principais contribuições e alguns desafios que devem ser superadas na utilização desse instrumento.

A partir de uma revisão sobre o tema cinema e ensino, identificamos algumas obras que abordam essa temática. A maioria busca ressaltar a importância do cinema como recurso 
pedagógico e facilitador da aprendizagem, assim como instrumento necessário e capaz de gerar uma melhor reflexão e criticidade nos alunos. Destacamos Holleben (2007), em sua obra Cinema e Educação: diálogo possível, no qual o cinema é um espaço de ensino e aprendizagem importante para a formação cultural e educacional das gerações presentes e futuras. A obra mostra o filme como um novo sistema de linguagem no registro da realidade que deve ser usado na educação escolar.

Buzzo (2004), ao discutir cinema e educação no Brasil, traz iniciativas e para estimular a produção de filmes educativos e organizar a utilização do cinema nas escolas. Christofoletti (2009) aborda dimensões como as da rotina do uso do filme na sala de aula, e questiona se existe uma capacitação docente nos cursos de formação de professores que orientem para a utilização desse recurso.

O cinema carrega em si outras possibilidades para o ensino, tanto para debates de conteúdos curriculares, quanto para temas que englobam a sociedade, pois propicia a formação de indivíduos mais críticos, aptos a refletirem a partir de variadas informações que chegam até eles pelos diversos meios de comunicação de massa, inclusive os dissiminados pela indústria cinematográfica.

O cinema como uma mídia presente no cotidiano da sociedade, não pode ser ignorado pela escola. Nesta perspectiva, Napolitano (2015) ressalta que:

Trabalhar com cinema em sala de aula é ajudar a escola a reencontrar a cultura ao mesmo tempo cotidiana e elevada, pois o cinema é o campo no qual a estética, o lazer, a ideologia e os valores sociais mais amplos são sintetizados numa mesma obra de arte. Assim, dos mais comerciais e descomprometidos aos mais sofisticados e "difíceis", os filmes têm sempre alguma possibilidade para o trabalho escolar (Id., 2015, p. 11-12, grifo do autor).

Obviamente, este recurso não deve adentrar o universo escolar apenas por modismos, com o intuito de mostrar que existe uma modernização e utilização de tecnologias (CAMPOS, 2006). Todavia, essa inserção deve ocorrer pelo fato de se reconhecer necessária essa educação para o cinema e com o cinema, evitando que não se repita a realidade de diversas instituições de ensino que possuem estrutura com salas vídeo e aparelhos para exibição de filmes, mas não o fazem, e quando, enfim, o fazem, não é da forma adequada.

Não podemos mais aceitar existir espaço na educação para a utilização do cinema apenas como mera ilustração do conteúdo, isso quando muito. Nem para suprir a falta de professores e planejamento. Filmes sem planejamento na escola não se configura como 
instrumento didático, mas apenas como sinônimo de "tapa buraco" ou "enrolação". A situação do filme como "tapa buraco" ocorre quando por problemas inesperados na escola, principalmente pela ausência de professores, usa-se o filme para suprir a carga horária. "Enrolação", quando sua exibição não possui ligação com a matéria ou conteúdo. Em ambos os casos, os alunos acabam associando essas experiências, ocasionando uma desvalorização desse instrumento como recurso didático (MORAN 1995 apud NAPOLITANO, 2015).

Buzzo (2004, p. 168) se referindo ao cinema e as suas potencialidades destaca que ele “[...] tem a vantagem da clareza na apresentação dos objetos, a possibilidade de desvelamento dos fenômenos naturais, satisfazendo a curiosidade e permitindo compreender e assimilar aquilo que de outra forma, pelos processos comuns, escaparia”.

Salvo a sua importância e diversas contribuições que o cinema pode proporcionar ao ensino, a utilização de filmes bem como de outros instrumentos didáticos não possuem poder para sanar e revolucionar o ensino no Brasil. Sua relevância é igual a dos tantos outros recursos audiovisuais existentes atualmente. Porém, o diferencial do filme está na ludicidade presente neste recurso, capaz de relacionar a escola, a cultura e a realidade do aluno.

Desse modo, entre as diversas disciplinas em que o filme vem sendo utilizado como instrumento didático, destacamos a Geografia, para analisarmos sua aplicabilidade no ensino, debates de temas e conceitos geográficos.

\section{O FILME COMO UM RECURSO DIDÁTICO NO ENSINO DE GEOGRAFIA}

“Os estudos envolvendo Geografia e cinema tiveram sua difusão na década de 1980, principalmente nos Estados Unidos, Inglaterra e Alemanha, vindo a se difundir no Brasil dez anos depois" (MOREIRA, 2011, p. 76). O mesmo autor destaca que, apesar dessa área de produção ter crescido no Brasil, os trabalhos, principalmente, mais aprofundados nesse tema, ainda são escassos (Ibid.).

Tavares (2011) em sua dissertação intitulada: Vem e vê. A utilização do filme no processo de ensino-aprendizagem de História e de Geografia, defende que o filme pode transformar-se num importante recurso pedagógico, principalmente, no ensino de Geografia, pois a experiência audiovisual permite facilitar a compreensão da realidade. A Geografia sendo uma disciplina responsável por desenvolver no aluno as habilidades de localizar, descrever, explicar e comparar fenômenos, os meio audiovisuais, sobretudo o filme, vão desempenhar o papel tanto de recurso didático quanto de instrumento de análise geográfica. 
Isso ocorre pelo fato do filme ter a capacidade de, pelas imagens em movimentos e linguagens utizadas, aproximar conceitos, noções de espaço e tempo, que as palavras podem não conseguir expressar com facilidade, dependendo do grau de cognição dos alunos.

Pensamos como Pontuschka et al. (2009, p. 280): "Para nós, geógrafos e professores de Geografia, o filme tem importância por que pode servir de mediação para o desenvolvimento das noções de tempo e de espaço na abordagem dos problemas sociais, econômicos e políticos". O filme é retratado como um facilitador no ensino de geografia, capaz de proporcionar, a partir de sua leitura, a compreensão de aspectos diversos que fazem parte da vida da sociedade moderna, com visão crítica dos conflitos e elementos constitutivos do espaço geográfico.

Fortalecendo esta ideia, Barbosa (2004, p. 112) afirma que:

O papel do filme na sala de aula é de provocar uma situação de aprendizagem para alunos e professores. A imagem cinematográfica precisa estar a serviço da investigação e da crítica a respeito da sociedade em que vivemos. Trata-se, portanto, de um movimento de apropriação cognitiva da relação espaço-imagem e, principalmente, da criação de sujeitos produtores de conhecimento e reconhecimento de si mesmos e do mundo.

Nesta perspectiva, o filme é visto como uma situação de aprendizado tanto para alunos quanto para professores, que precisa estar a serviço da investigação e da crítica. Para tanto, podemos usar o fime para a leitura, debate e análise do espaço geográfico. Assim, a Geografia constitui-se de uma ciência rica e repleta de conceitos que possibilitam entender e se relacionar melhor em sociedade a partir da sua leitura de mundo.

"Como ciência social, a Geografia tem como objeto de estudo a sociedade que, no entanto, é objetivada via cinco conceitos-chave, [...] todos se referem à ação humana modelando a superfície terrestre: paisagem, região, espaço, lugar e território." (CORRÊA, 2000, p.16). E a imagem cinematográfica é um recurso que pode ser utilizado para se trabalhar esses e outros conceitos referentes a ciência geográfica, especialmente pela forma que a indústria do cinema se apropria desses conceitos para a construção dos seus enredos e narrativas. Além disso, podemos utilizá-lo como as diversa paisagens são retratadas em obras fílmicas, suas peculiaridades e veracidades. Através desse instrumento é possível visualizar diferentes regiões do globo e suas características, como: cultura, língua, vestimentas, costumes, entre outros. 
Para tanto, podemos listar temas que explorem as diversas e constantes lutas por territórios responsáveis por gerar conflitos étnicos, religiosos e muitas vezes guerras civis, que acabam ocasionando a migração de grande número de pessoas do seu lugar de convivio e de identidade; os problemas urbanos presentes nas grandes cidades; a problemática ambiental. Constituem-se temas atuais que já foram campo de debates e histórias narradas pela indústria cinematográfica. Existe uma lista imensa de filmes com variados gêneros que proporciona uma leitura geográfica que pode tornar possível o debate e reflexão de temas diversos nas aulas de Geografia (NAPLITANO, 2015).

Sobre o assunto, Pontuschka, Paganelli e Cacete (2009, p. 281) enfatiza que:

As imagens sonorizadas do cinema também podem lidar com espaços e tempos diferentes. Mesmo os filmes comerciais podem trazer elementos para a reflexão pedagógica, permitindo ao professor - em nosso caso, o de Geografia - realizar uma análise crítica do filme. Como arte e como linguagem rica de conteúdos que, embora sejam ficcionais, podem ter se expelhado em fatos reias ou na vasta literatura disponível.

Os filmes comerciais se constituem uma opção quando tratamos a importância de levar o cinema para as aulas de Geografia. Diferentemente do que ocorre com a maioria das produções didáticas, os filmes comerciais com seus variados gêneros de ficção fazem parte do nosso cotidiano. "Obras que foram produzidas para a chamada 'película' de filme e depois convertidos em formato VHS ou DVD, o que, diga-se, tem permitido seu uso escolar com maior agilidade.” (NAPOLITANO, 2015, p. 11, grifo do autor). Esses filmes, apesar de não serem criados diretamente para o uso pedagógico, trazem a possibilidade de se abordar vários temas no ensino em geral e da Geografia, e de se criar expectadores mais críticos e exigentes quanto a cultura cinematográfica.

Seja na Geografia ou em qualquer outra disciplina, os filmes não devem ser utilizados apenas como uma ilustração de conteúdos e temas avulsos. O professor deve atuar como mediador, norteando o debate e levantando questões que provoquem a reflexão do aluno, seguindo o ponto de vista que "Ler um filme geograficamente é, portanto, mais do que procurar nele conteúdos comumente trabalhados por geógrafos. É entendê-lo como dotado de geograficidade. É perceber sua espacialidade e tentar entender seus significados” (BLUWOL, 2008, p. 2) 
Traremos, a seguir, as experiências e resultados obitidos a partir de um estudo de caso, nas turmas do $6^{\circ}$ ano "A" e $9^{\circ}$ ano "turma única" anos da Escola Municipal Abraão Cavalcante Bessa para investigar se o filme é um instrumento utilizado na disciplina de Geografia e como consiste sua utilização.

\section{A EXPERIÊNCIA NA ESCOLA MUNICIPAL ABRÃ̃O CAVALCANTE BESSA}

A estrutura da escola Municipal Abraão Cavalcante Bessa é composta de salas de aulas forradas, climatizadas, quadro branco, datashow e bebedouros, sala de professores, diretoria, sala de vídeo, sala multifuncional, biblioteca, laboratório de informática, pátio, entre outros ambientes, permitindo em sua estrutura a utilização de filmes no espaço escolar.

E ao entrevistármos o professor licenciado em Geografia que leciona do $6^{\circ}$ ao $9^{\circ}$ anos, identificamos que o mesmo tem oito anos de experiência em sala de aula. Com essa entrevista, visamos investigar se o filme é um recurso utilizado na disciplina, bem como os pontos positivos e negativos que ele observa na utilização desse recurso didático-pedagógico.

Atráves da entrevista realizada, o professor revela fazer uso de filmes na disciplina de Geografia, apesar de na sua formação acadêmica ter acontecido minimamente um incentivo ou orientação para utilização desse recurso. Sobre essa limitação na formação, o professo afirma que foi utilizado "Muito pouco. Só em disciplinas da área de ensino, víamos alguns textos de como utilizar o filme em sala de aula, um incentivo a grosso modo".

Ao questionarmos quais os aspectos positivos e negativos ao se trabalhar com o filme como um recurso didático na sala de aula, a resposta foi a seguinte:

- Os aspectos positivos é que o filme vem ilustrar o conteúdo que foi
ministrado em sala de aula, fazendo os alunos entenderem melhor o assunto
que foi repassado. Entre os pontos negativos, muitas vezes os alunos
encaram o filme apenas como uma diversão. Como nossa formação é
deficiente, não houve um incentivo e orientação adequada, isso dificulta na
escolha do filme, no planejamento e metodologia para trabalhá-lo como
recurso didático. A duração da maioria dos filmes que excedem as horas
aula. No $6^{\circ}$ ano tenho uma carga horária de duas aulas semanais, no $9^{\circ}$ ano
são 4 aulas, dependendo da duração do filme, se ele for muito longo haverá
uma quebra, e considero isso um aspecto negativo. Devido a essas
dificuldades eu chego a trabalhar com dois ou três filmes por ano, disse o
professor.

$\mathrm{Na}$ fala do professor, percebemos que os filmes ainda são utilizados apenas como recurso para ilustração de conteúdos e não como instrumentos para investigação, análise e 
debates. Contudo, sabemos que é possível, através do filme, visualizarmos diferentes paisagens, problemas sociais, econômicos, a dinâmica urbana das grandes cidades, entre outros temas da geografia, já que filmes são produções e reproduções carregadas de ideologias e significados, é artifício de manipulação e interpretação (BERNADET, 2000), que devem ser analisados criticamente pelos alunos e professores.

"Utilizando desse recurso como meio para despertar a curiosidade dos alunos, entendendo que eles não possuem a capacidade de compreenderem intrinsicamente os aspectos abordados pelo filme", disse o professor. Utilizamos esse trecho para grifar a importância do professor como mediador na utilização desse recurso, fazendo ponte entre o conhecimento do aluno e as temáticas abordadas nos filmes, instigando a análise crítica dos fenômenos representados. Nesse quesito, é de suma importancia que a escolha do filme seja adequada ao público destinado, para que estes possuam maturidade a fim de compreender as informações tratadas.

Os pontos negativos citados são comuns, principalmente em relação a carga horária da disciplina e a duração dos filmes. Fato que pode ser superado de várias formas, identificando, de início, as produções que duram entre 90 a 115 minutos, que se encaixam em duas horas aulas. Existe, ainda, a possibilidade de se negociar a aula de outro professor no dia da exibição ou ainda fazer uma contextualização do filme e apresentar apenas trechos de algumas cenas. Quanto ao fato dos alunos não levarem a sério esse recurso, considerando-o como diversão ou entretenimento, cabe ao professor instruí-los sobre a importância e os objetvos da ativididade realizada.

Através de um questionário, contendo perguntas abertas (2), fechadas (3) e de múltiplas escolhas (2), aplicado com os alunos do $6^{\circ}$ "A" e $9^{\circ}$, em turmas únicas cada, perfazendo um total de 43 alunos, buscamos identificar a relação dos alunos com o cinema no seu cotidiano questionando quantos filmes eles assistem mensalmente; qual a modalidade que mais lhes interessam; as opiniões desse público acerca do uso de filmes no ensino de Geografia e quais as disciplinas que mais utilizam dessa ferramenta como recurso didático.

Diante dos dados obtidos e das análises realizadas a partir da aplicação do questionário, podemos constatar que os filmes são recursos que se fazem pesentes no cotidiano dos alunos. Ao levantarmos o questionamento se o ato de assistir filmes caracterizase por ser interessante (legal) ou dessinteressante (chato), todos os entrevistados concordaram ser este um recurso interessante. 
Na tabela a seguir (figura 02), estão os dados da frequência mensal da visualização de filmes por alunos, em que subdividimos em categorias e com os seguintes critérios para avaliação: menos de cinco (razoável), mais de cinco (bom), mais de dez (ótimo) e nenhum. A maioria da vizualização desses filmes acontecem em casa por meio do acesso à internet, ou com aparelhos de reprodução de filmes. Já que a maior parte do público investigado não tem acesso as salas de exibição dos cinemas, por ser algo que se restringe mais ao grandes centros urbanos e não a cidades de pequeno porte, como é o caso de Taboleiro Grande/Rn.

\begin{tabular}{ccccc} 
Alunos & \multicolumn{4}{c}{ Frequência mensal da visualização de filmes } \\
& Menos de cinco & Mais de cinco & Mais de dez & Nenhum \\
$\mathbf{6}^{\mathbf{0}}$ ano & 15 & 1 & 5 & 2 \\
$\mathbf{9}^{\mathbf{0}}$ ano & 5 & 4 & 11 & 0
\end{tabular}

Figura 02: Tabela contendo dados da frequência mensal da visualização de filmes Fonte: Entrevista com os alunos.

A partir dessa tabela percebemos que a turma de $6^{\circ}$ ano apresenta menor frequência na visualização de filmes, uma vez que, de 23 alunos, 15 responderam assistir menos de cinco filmes ao mês, o que através dos nossos critérios consideramos uma quantia razoável, principalmente se levarmos em conta a faixa etária desses alunos, que se encontram entre $10 \mathrm{e}$ 12 anos. Já a turma de $9^{\circ}$ ano apresenta maior número de visualizações, destacando que dos 20 alunos, 11 responderam assistir mais de dez filmes a cada mês, fato considerado ótimo.

Em suma, esses dados são de fundamental importância porque nos apontam que esse instrumento se faz presente no cotidiano dos alunos, e por este fato não pode ser ignorado pela escola, que deve utílizá-lo como recurso didático tanto para debates de temas curriculares quanto de temas pertinentes a sociedade (ética, saúde, orientação sexual, pluralidade cultural entre outros sugeridos pelos PCN's), incentivando e preparando os discentes para uma melhor análise do que é disseminado e reproduzido pela indústria cinematográfica.

Ao questionarmos qual o gênero de filmes que mais lhes interessam, obtivemos os resultados expressos na figura 03, em que a modalidade ação/aventura nas duas séries foram as mais citadas. Nas alternativas dessa questão, incluímos também a opção dos filmes educativos aqueles que foram criados para o uso didático em sala de aula, porém, como não foi citado por nenhum dos alunos, não incluímos na tabela. 


\begin{tabular}{lccccc} 
Alunos & \multicolumn{5}{c}{ Gêneros de filmes mais visualizados } \\
& Ficção & $\begin{array}{c}\text { Ação/ } \\
\text { Aventura }\end{array}$ & Romance & Terror & Documentários \\
$\mathbf{6}^{\mathbf{0}}$ ano & 0 & 14 & 2 & 6 & 1 \\
$\mathbf{9}^{\mathbf{0}}$ ano & 1 & 16 & 2 & 1 & 0 \\
\hline
\end{tabular}

Figura 03: Tabela dos gêneros de filmes mais visualizados pelos alunos

Fonte: Entrevista com os alunos.

Observando o resultado, Napolitano (2015) destaca que ação/aventura e ficção científica são os gêneros mais preferidos nessa faixa etária, enquanto que as meninas tendem a demonstrar interesse por filmes românticos, referindo-se ao público do Ensino Fundamental II.

Esses gêneros não caem somente no gosto do público jovem, pesquisas divulgadas pelo The Numbers (2016), site especializado em números de faturamento e bilheterias do cinema mundial, divulgou uma pesquisa realizada entre 1995 e 2016, das quais as modalidades que mais faturam seriam aventura, seguida por comédia e ação. Diferentemente dos filmes comerciais, que são responsáveis pelo entretenimento de um grande e variado número de pessoas, os didáticos ainda são caracterizados muitas vezes como cansativos e "chatos" pelos alunos.

Conjugaremos a seguir duas perguntas feitas que objetivaram conhecer a opinião dos alunos sobre o uso de filmes como instrumento didático, são elas: Você acha possível aprender conteúdos escolares através de filmes? Você acha possível aprender Geografia através do uso de filmes? A essas perguntas, $100 \%$ dos alunos respoderam que é possível aprender conteúdos escolares e da Geografia através do uso de filmes na escola. Consideramos essas respostas de fundamental importância, pois elas nos proporcionam conhecer o ponto de vista desse público em relação a utilização do recurso investigado. Quando questionados se já assistiram filmes na escola e qual a disciplina, as mais citadas estão descritas seriam em História, Ciências e Geografia (figura 04):

\begin{tabular}{|ccccc} 
Alunos & \multicolumn{3}{c|}{ Disciplinas em que os filmes são utilizados como recurso } \\
& Geografia & História & Ciências & Ensino Religioso \\
& 3 & 14 & 5 & 1 \\
$\mathbf{6}^{\mathbf{0}}$ ano & 2 & 15 & 3 & 0 \\
\hline $9^{0}$ ano & &
\end{tabular}

Figura 04: Tabela sobre as disciplinas que mais utilizam filmes na escola

Fonte: Entrevista com os alunos. Elaborada pela autora. 
O resultado que mostra a disciplina de História como umas das disciplinas que mais recorrem ao uso de filmes, Napolitano (2015, p. 38) ressalta que a "História é uma das disciplinas mais afeitas a atividades com cinema". Isso se dá principalmente pelo número de produções que retratam fatos importantes sobre os períodos históricos do Brasil e do mundo; A Geografia encontra-se, então, como uma das mais utilizadas, embora a fala do professor da disciplina relata que:

- Dependendo do conteúdo eu gosto de trabalhar com filmes ou documentários. Pois os mesmos tendem a despertar a curiosidade dos alunos, a partir do momento em que utilizamos de instrumentos que despertem a curiosidade do aluno, estamos estimulando eles a querer aprenderem mais. Por isso, eu gosto de utilizar filmes nas minhas aulas, pelo menos um em cada bimestre, disse o professor.

Consideramos este um número razoável para o uso desse recurso, haja vista ser necessário um planejamento antecipado para que sua utilização não aconteça apenas como forma de substituir a falta de professores ou imprevistos, mas que possua objetivos definidos, antecipadamente. Na verdade, não existe uma quantia determinada para a utilização por bimestre ou semestres dessa ferramenta, isso vai acontecer de acordo com o planejamento e realidade de cada ambiente escolar. O que reiteramos é a necessidade de se utilizar o filme no ensino e para o ensino.

Indagamos aos alunos se eles gostariam que o professor de Geografia fizesse uso de filmes em sua disciplina e com maior frequência. Na turma de $6^{\circ}$ A e $9^{\circ}$ anos, todos responderam que "sim", gostariam que esse recurso fosse mais utilizado. Segundo as justificativas dos alunos, podemos destacar:

“- Por ser mais interessante prestamos mais atenção", disse o aluno "X" do 6 A;

“- Porque só assim não escrevemos tanto", disse o aluno "B” do $6^{\circ} \mathrm{A}$;

“- Porque filmes são muito legais, quando o professor fala muito me dá sono”, disse o aluno "Y" do $6^{\circ} \mathrm{A}$;

“- Porque atráves de filmes a gente aprende mais porque não ficamos só ouvindo, mas vemos também as coisas", disse o aluno "Z" do $9^{\circ}$ ano;

“- Porque é um tipo de aula interessante e diferente", disse o aluno "K" do $9^{\circ}$ ano;

Diante dos trechos das respostas dos alunos citados anteriormente, compreendemos que o filme se constitui como um diferencial, um instrumento didática e lúdica possível para o trabalho e debate de temas na sala de aula. Uma metodologia que pode ser utilizada como 
meio de tentar superar o ensino de uma Geografia descritiva e cansativa, como relata o alunos "Y", as vezes, "dá sono". Apesar das suas potencialidades e ludicidade, este recurso necessita estar a serviço da investigação, análise e criticidade de seus visualizadores e apreciadores, seja como instrumento didático, em salas de exibição ou na comodidade de nossa casa.

Traremos a seguir (figura 05) algumas indicações de filmes que podem ser trabalhados no Ensino Fundamental II nas séries do $6^{\circ}$ e $9^{\circ}$ anos. Utilizando os Parâmetros Curriculares Nacionais (PCN) de Geografia para identificar os temas propostos para o ensino desta disciplina nas séries citadas. Nas indicações, foram observados critérios como: temática/conteúdo, duração aula/filme, público-alvo/classificação indicativa, entre outros.

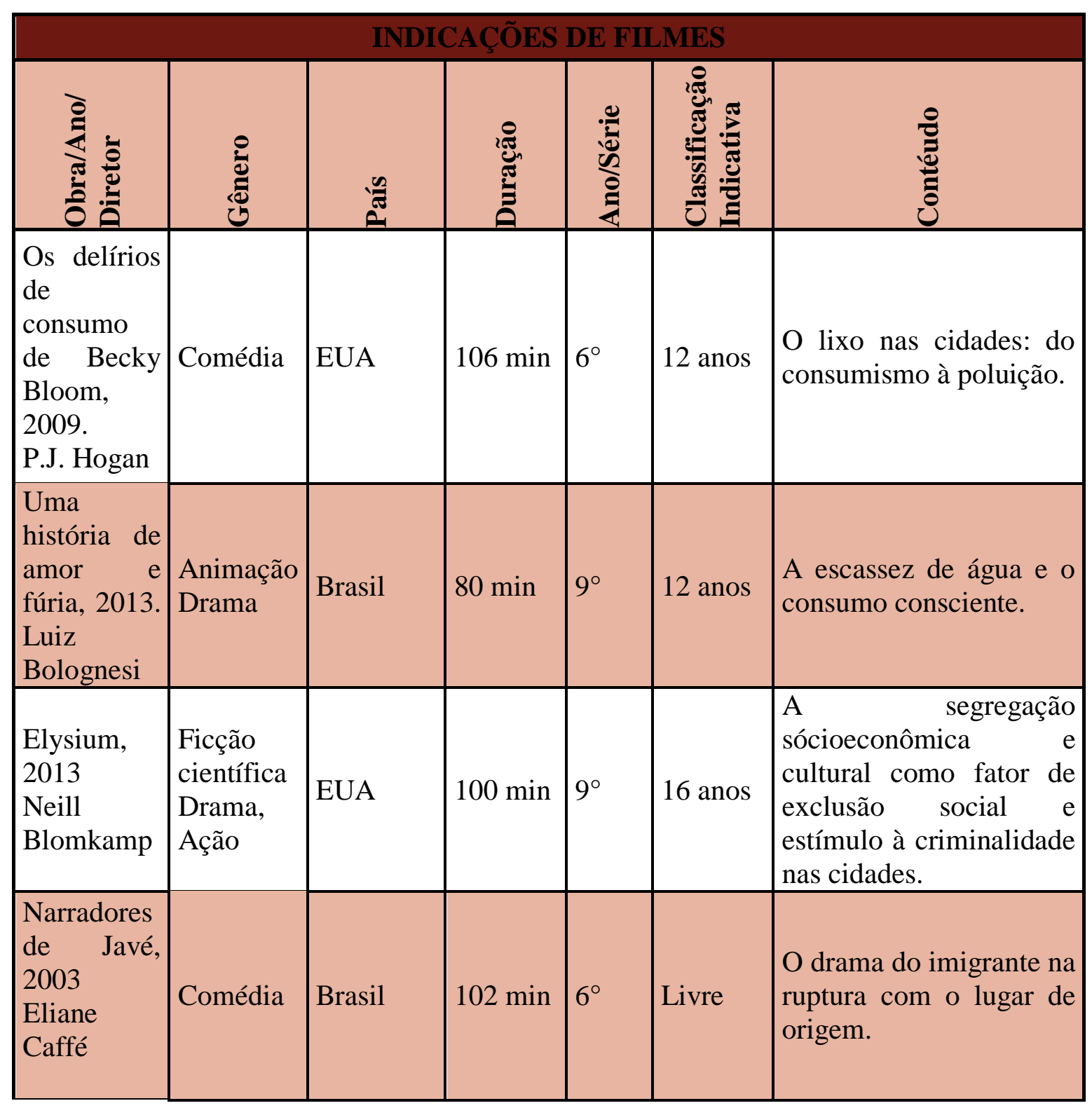




\begin{tabular}{|c|c|c|c|c|c|c|}
\hline $\begin{array}{l}\text { Rio 2, 2014 } \\
\text { Carlos } \\
\text { Saldanha }\end{array}$ & $\begin{array}{l}\text { Animação } \\
\text { Aventura }\end{array}$ & EUA & $101 \mathrm{~min}$ & $6^{\circ}$ & Livre & $\begin{array}{l}\text { Urbanização } \\
\text { degradação ambiental. }\end{array}$ \\
\hline $\begin{array}{l}118 \text { dias, } \\
2015 \\
\text { Steve } \\
\text { Loter }\end{array}$ & Drama & EUA & $103 \mathrm{~min}$ & $9^{\circ}$ & 14 Anos & Conflitos internacionais. \\
\hline $\begin{array}{l}\text { Brasil } \\
\text { animado, } \\
2011 . \\
\text { Mariana } \\
\text { Caltabiano }\end{array}$ & $\begin{array}{l}\text { Anima- } \\
\text { ção }\end{array}$ & Brasil & $78 \mathrm{~min}$. & $6^{\circ}$ & Livre & $\begin{array}{l}\text { Pluralidade cultural e } \\
\text { paisagens brasileiras. }\end{array}$ \\
\hline $\begin{array}{l}\text { Era Uma } \\
\text { Vez... } \\
2008 \\
\text { Breno } \\
\text { Silveira }\end{array}$ & $\begin{array}{l}\text { Drama } \\
\text { Romance }\end{array}$ & Brasil & $117 \mathrm{~min}$ & $6^{\circ}$ & 14 anos & $\begin{array}{l}\text { Modos de vida urbano e } \\
\text { qualidade de vida. }\end{array}$ \\
\hline $\begin{array}{l}\text { dia } \\
\text { depois de } \\
\text { amanhã, } \\
2004 . \\
\text { Roland } \\
\text { Emmerich }\end{array}$ & $\begin{array}{l}\text { Ação, } \\
\text { Ficção } \\
\text { científica }\end{array}$ & EUA & $120 \mathrm{~min}$ & $9^{\circ}$ & Livre & Alterações Climáticas. \\
\hline $\begin{array}{l}\text { O menino } \\
\text { do pijama } \\
\text { listrado, } \\
2008 . \\
\text { Mark } \\
\text { Herman }\end{array}$ & Drama & $\begin{array}{l}\text { EUA, } \\
\text { Reino } \\
\text { Unido }\end{array}$ & $94 \min$ & $9^{\circ}$ & 12 anos & $\begin{array}{lr}\text { Segunda } & \text { Guerra } \\
\text { Mundial } & \text { (Alemanha } \\
\text { Nazista). } & \end{array}$ \\
\hline $\begin{array}{l}\text { O caminho } \\
\text { das nuvens, } \\
2003 . \\
\text { Vicente } \\
\text { Amorim }\end{array}$ & Drama & Brasil & $87 \mathrm{~min}$ & $9^{\circ}$ & 12 anos & $\begin{array}{l}\text { Formas de produção e } \\
\text { relações de trabalho no } \\
\text { desenvolvi-mento } \\
\text { desigual do território } \\
\text { brasileiro. }\end{array}$ \\
\hline $\begin{array}{l}\text { Tainá } 3-\mathrm{A} \\
\text { Origem, } \\
2013 \\
\text { Rosane } \\
\text { Svartman }\end{array}$ & Aventura & Brasil & $80 \mathrm{mim}$ & $6^{\circ}$ & Livre & $\begin{array}{l}\text { Florestas tropicais: a } \\
\text { Amazônia } \quad \text { e } \\
\text { megadiversida-de } \\
\text { mundo tropical. }\end{array}$ \\
\hline
\end{tabular}

Figura 05: Quadro contendo sugestões de filmes para o uso didático na disciplina de Geografia.

Fonte: ADORO CINEMA, 2016. PCN's de Geografia (BRASIL, 1998). 


\section{CONSIDERAÇÕES FINAIS}

Esse trabalho buscou investigar e discutir o uso dos filmes no ensino de Geografia, bem como as potencialidades e eventuais problemas na utilização de filmes no ambiente escolar, principalmente na Escola Municipal Abraão Cavalcante Bessa, nosso campo de pesquisa. Reiteramos ser este de fato um instrumento didático-pedagógico promissor, caracterizado pela sua ludicidade e presença no cotidiano dos alunos. Mas, que ainda enfrenta dificuldades para sua inserção correta no ensino, em que deixe de ser utilizado apenas como ilustração de contéudos para ser instrumento de investigação, debates e formador de opinião.

A sua inserção nas salas de aulas de diversas disciplinas, inclusive de Geografia, já um caminho, mas, é de fundamental importância que nos cursos de licenciatura ocorra com maior intensidade a preparação e incentivo dos profssionais da educação para a utilização do filme na sala de aula.

A verdade é que, embora as diversas transformações que cinema tenha experimentado ao longo dos anos, ainda é o responsável por encantar e fascinar gerações, seja qual for a idade, a raça, a cultura, a mais de duzentos anos ele vem se reiventando e conquistando cada vez mais de crianças a jovens e adultos. Diante de tais fatos, os filmes não podem ser ignorados pela escola.

\section{REFERÊNCIAS}

ADORO CINEMA. Disponível: http://www.adorocinema.com/ Acesso em 18 out. 2016.

BARBOSA, Jorge Luiz. Geografia e Cinema: Em Busca de Aproximações e do Inesperado. In: CARLOS, Ana Fani Alessandri (Org.). A geografia na sala de aula. 8 ed. São Paulo: Contexto, 2004, p. 109-133.

BERNADET, Jean-Claude. O que é cinema. São Paulo: Brasiliense, 2000. Disponível em: https://www.academia.edu/3746096/O_Que_\%C3\%A9_Cinema_-_Jean_Claude_Bernadet.

Acesso em: 28 mai. 2016.

BLUWOL, Dennis Zagha. Uma Geografia do Cinema: Imagens do Urbano. Dissertação (Mestrado em Geografia). Pontfícia Universidade Católica de São Paulo, PUC-SP, 2008. p. 120. Disponível em: https://sapientia.pucsp.br/bitstream/handle/12334/1/Dennis\%20Zagha\%20Bluwol.pdf. Acesso em: 28 de mai. 2016. 
BRASIL. Ministério da Educação. Secretaria da Educação Fundamental. Parâmetros Curriculares Nacionais: Geografia. Brasília: MEC/SEf, 1998. 156p. Disponível em: http://portal.mec.gov.br/seb/arquivos/pdf/geografia.pdf. Acesso em: 09 jul. 2016.

BUZZO, Cristina. Filme "Ensinante": o interesse pelo cinema educativo no Brasil. Proposições, v. 15. n. 1. Jan./abr. 2004. Disponível em: http://www.proposicoes.fe.unicamp.br/proposicoes/textos/43-artigos-bruzzoc.pdf Acesso em: 09 de jul. 2016

CAMPOS, Rui Ribeiro. Cinema, geografia e sala de aula. Estudos Geográficos, Rio Claro, 4 (1): 1-22, Junho - $2006 . \quad$ Disponível em: http://www.educadores.diaadia.pr.gov.br/arquivos/File/agosto2011/geografia_artigos/6art_cin ema_geografia.pdf. Acesso em: 28 de mai. 2016.

CHRISTOFOLETTI, Rogério. Filmes na sala de aula: recurso didático, abordagem pedagógica ou recreação? Revista educação. Santa Maria, v. 34, n. 3, p. 603-616, set./dez. 2009. Disponível em: https://periodicos.ufsm.br/reveducacao/article/view/871/605. Acesso em: 15 abr. 2016.

CORREAA, Roberto Lobato. Espaço: um conceito-chave da geografia. In: CASTRO, Iná Elias de; GOMES, Paulo Cesar da Costa. Geografia: Conceitos e temas. $2^{\mathrm{a}}$ ed. Rio de Janeiro: Bertrand Brasil, 2000, p. 15-47.

DUARTE, Rosália. Cinema e Educação. 3. ed. Belo Horizonte: Autêntica Editora, 2009.

GIL, Antonio Carlos. Como elaborar projetos de pesquisa. São Paulo: Atlas, 1988.

HOLLEBEN, Índia Mara Aparecida Dalavia de Souza. Cinema e educação: Diálogo possível. Dissertação (Mestrado) - Ponta Grossa, 2007. Disponível em: http://www.diaadiaeducacao.pr.gov.br/portals/pde/arquivos/462-2.pdf. Acesso em: 25 abr. 2016.

LADIM, Marisa. O Primeiro Cinema e o cinema Contenporâneo: Algumas aproximações. Rio de Janeiro: Contemporânea, 2008. Edição Especial, v. 6, n. 03. Disponível em: http://www.contemporanea.uerj.br/pdf/ed_11ex/03_MarisaLANDIM_IISeminarioPPGCOM.p df. Acesso em: 25 abr. 2016.

MASCARELlO, Fernando. (Org.). História do Cinema Mundial. Campinas, SP: Papirus, 2006. Disponível em: http://sesc-se.com.br/cinema/historia+do+cinema+mundial.pdf. Acesso em: 09 ago. 2016. 
MOREIRA, Tiago de Almeida. Geografia e Cinema do Brasil: Estado da Arte. Revista Eletrônica: Tempo - Técnica - Território, v. 2, n. 1, (2011), p. 95-118, ISSN: 2177-4366. Disponível em: http://inseer.ibict.br/ciga/index.php/ciga/article/viewFile/194/146. Acesso em: 28 mai. 2016.

NAPOLITANO, Marcos. Como usar o cinema na sala de aula. 5. ed. São Paulo: Contexto, 2015.

PONTUSCHKA, Nídia Nacb; PAGANELLI, Tomoko Lídia; CACETE, Núria Hanglei. A linguagem cinematográfica no ensino de Geografia. In: Para ensinar e aprender Geografia. 3. ed. São Paulo: Cortez, 2009, p. 261-283.

ROMARIZ, Thiago. Cinema mundial bate recorde histórico em arrecadação. Disponível em: https://omelete.uol.com.br/filmes/noticia/cinema-mundial-bate-recorde-historico-emarrecadacao/. Acesso em: 06 de out. 2016.

TAVARES, Marisa Ferreira. Vem e vê. A utilização do filme no processo de ensinoaprendizagem de História e de Geografia. Dissertação (Mestrado). Universidade do Porto, 2011, 210 p. Disponível em: https://sigarra.up.pt/flup/pt/pub_geral.show_file?pi_gdoc_id=475104 Acesso em: 09 ago. 2016.

THE NUMBERS. Disponível em: http://www.the-numbers.com/market/genres. Acesso em: 06 out. 2016. 